\title{
Phthalocyanines as Molecular Scaffolds to Block Disease-Associated Protein Aggregation
}

\author{
Ariel A. Valiente-Gabioud, ${ }^{\dagger \neq}$ Marco C. Miotto, ${ }^{\dagger \neq}$ María E. Chesta, ${ }^{\dagger \dagger}$ Verónica Lombardo, ${ }^{\dagger \neq}$ \\ Andres Binolfi, ${ }^{\dagger, \dagger}$ and Claudio O. Fernández $z^{*,+\hbar}$
${ }^{\dagger}$ Max Planck Laboratory for Structural Biology, Chemistry and Molecular Biophysics of Rosario (MPLbioR, UNR-MPIbpC) and ${ }^{\ddagger}$ Instituto de Investigaciones para el Descubrimiento de Fármacos de Rosario (IIDEFAR, UNR-CONICET), Universidad Nacional \\ de Rosario, Ocampo y Esmeralda, S2002LRK Rosario, Argentina
}

CONSPECTUS: The aggregation of proteins into toxic conformations plays a critical role in the development of different neurodegenerative diseases such as Alzheimer's disease (AD), Parkinson's disease (PD), and Creutzfled-Jakob's disease (CJD). These disorders share a common pathological mechanism that involves the formation of aggregated protein species including toxic oligomers and amyloid fibrils. The aggregation of alpha-synuclein $(\alpha \mathrm{S})$ in $\mathrm{PD}$ and the amyloid beta peptide $(\mathrm{A} \beta)$ and tau protein in $\mathrm{AD}$ results in neuronal death and disease onset. In the case of CJD, the misfolding of the physiological prion protein $(\operatorname{PrP})$ induces a chain reaction that results in accumulation of particles that elicit brain damage. Currently, there is no preventive therapy for these diseases and the available therapeutic approaches are based on the treatment of the symptoms rather than the underlying causes of the disease. Accordingly, the aggregation pathway of these proteins represents a useful target for therapeutic intervention. Therefore, understanding the mechanism of amyloid formation and its inhibition is of high clinical importance. The

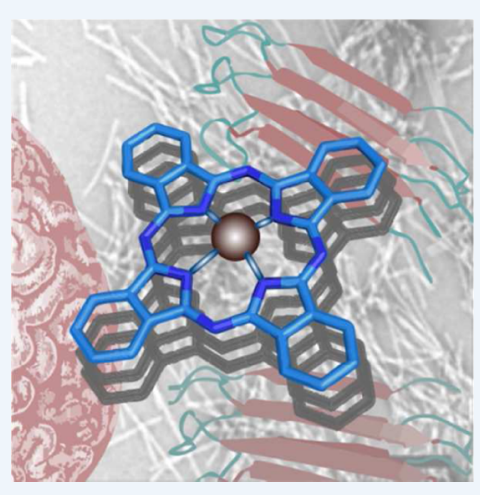
design of small molecules that efficiently inhibit the aggregation process and/or neutralize its associated toxicity constitutes a promising tool for the development of therapeutic strategies against these disorders. In this accounts, we discuss current knowledge on the anti-amyloid activity of phthalocyanines and their potential use as drug candidates in neurodegeneration. These tetrapyrrolic compounds modulate the amyloid assembly of $\alpha \mathrm{S}$, tau, $\mathrm{A} \beta$, and the $\operatorname{PrP}$ in vitro, and protect cells from the toxic effects of amyloid aggregates. In addition, in scrapie-infected mice, these compounds showed important prophylactic antiscrapie properties. The structural basis for the inhibitory effect of phthalocyanines on amyloid filament assembly relies on specific $\pi-\pi$ interactions between the aromatic ring system of these molecules and aromatic residues in the amyloidogenic proteins. Analysis of the structure-activity relationship in phthalocyanines revealed that their anti-amyloid activity is highly dependent on the type of metal ion coordinated to the tetrapyrrolic system but is not sensitive to the number of peripheral charged substituents. The tendency of phthalocyanines to oligomerize (self-association) via aromatic-aromatic stacking interactions correlates precisely with their binding capabilities to target proteins and, more importantly, determines their efficiency as anti-amyloid agents. The ability to block different types of disease-associated protein aggregation raises the possibility that these cyclic tetrapyrrole compounds have a common mechanism of action to impair the formation of a variety of pathological aggregates. Because the structural and molecular basis for the anti-amyloid effects of these molecules is starting to emerge, combined efforts from the fields of structural, cellular, and animal biology will result critical for the rational design and discovery of new drugs for the treatment of amyloid related neurological disorders.

\section{PHTHALOCYANINES AND AMYLOIDOSIS}

Neurodegenerative diseases such as Alzheimer's disease (AD), Parkinson's disease (PD), and Creutzfeldt-Jakob's disease (CJD) are characterized by the progressive loss of neuronal cells and the decline of cognitive and motor functions. Different biochemical, genetic, and neuropathological studies support the role of protein amyloidogenesis in the development of these disorders. ${ }^{1,2}$ Briefly, the protein aggregation process starts with the formation of transient oligomeric species with pronounced $\beta$-sheet secondary structure, that evolve into larger, prefibrillar architectures which ultimately form mature amyloid fibrils. Although recent studies have suggested that intermediate species play a key role in the neurodegenerative process, ${ }^{3}$ the precise mechanism(s) behind conversion and self-assembly of naturally occurring innocuous proteins into neurotoxic conformations remains a mystery.

The discovery of small molecules targeting disease-associated protein aggregation is considered a promising therapeutic strategy toward neurodegenerative disorders. ${ }^{4}$ From the screening of large libraries of small compounds, a range of potential candidates were found to modulate the aggregation of amyloid proteins such as the prion protein $(\operatorname{PrP})$, involved in CJD, alpha-synuclein $(\alpha S)$, involved in $\mathrm{PD}$, and the amyloid beta peptide $(\mathrm{A} \beta)$ and tau protein, involved in $\mathrm{AD}^{5-12}$ Notably, polyaromatic scaffolds belonging to the chemical

Received: November 13, 2015

Published: May 2, 2016 
classes of porphyrins, flavonoids, phthalocyanines, and polyphenols were predominantly represented in screenings for anti-amyloidogenic compounds. ${ }^{5-12}$

Particularly, phthalocyanines were shown to exhibit antiscrapie activity and inhibition of $\alpha \mathrm{S}$, tau, and $\mathrm{A} \beta$ amyloid assembly. ${ }^{11-19}$ These molecules are cyclic tetrapyrroles, a class of compounds including the porphyrin family of hemes and chlorophylls, and whose distinguished characteristic is the planarity of its aromatic ring system. Indeed, the polarizable and $\pi$-electron delocalized ring system of phthalocyanines represent the structural element that contribute mostly to the ability of these molecules to bind strongly and selectively to aromatic amino acids in proteins via $\pi-\pi$ interactions and induce marked modifications in their native states. Since the amyloid assembly process involves changes in conformation of the aggregated proteins, phthalocyanine-based compounds were then proposed to serve as inhibitors of the conversion process. Added to that, the frequent occurrence of aromatic residues in diverse fragments of unrelated amyloid-forming proteins suggests that $\pi-\pi$ interactions might serve as structural and functional elements for the progression of the self-assembly process. These evidence rendered phthalocyanines as a promising class of amyloid inhibitors.

Interestingly, when considered as therapeutic candidates, phthalocyanines show numerous advantages: (i) low toxicity, as attested from studies using animal models, ${ }^{10,13,20,21}$ (ii) successful use and administration in humans for cancer treatments that relied on radiotherapy and photodynamicbased protocols, ${ }^{22}$ and (iii) well-documented synthetic chemistry methods and availability of large libraries containing structurally diverse variants (i.e., different metals at the central cavity and a wide variety of chemical groups at the periphery of the tetrapyrrolic system) (Figure 1). ${ }^{23-26}$ The latter is particularly interesting in order to develop phthalocyanines with enhanced anti-amyloid activity since, as will be discussed in the following sections, both the nature of the metal ions conjugated to the central nitrogens and the properties of the functional groups anchored at the periphery of the aromatic macrocycle act as critical elements for the physicochemical properties of phthalocyanines (i.e., water solubility, intrinsic tendency to self-association), ${ }^{27,28}$ as well as for their antiamyloid activity and binding features to target protein sites.

\section{AMYLOID-BLOCKING EFFECTS IN VITRO AND IN VIVO}

Distinct variants of phthalocyanines and porphyrins have been tested for their capability to interfere with the amyloid assembly process of proteins linked to neurodegeneration. The phthalocyanine tetrasulfonate (PcTS) compounds are among the most widely investigated tetrapyrroles. The structure of PcTS, depicted in Figure 1, contains four sulfonic acid groups at the borders of the aromatic rings, whereas the center of the molecule can remain ligand-free or coordinated to metal ions of various valences.

The pathogenesis of prion diseases is associated with the conversion of the normal, functional state of the prion protein $\left(\operatorname{PrP}^{\mathrm{c}}\right)$ to a misfolded, protease resistant, and toxic species termed scrapie $\left(\operatorname{PrP}^{\mathrm{sc}}\right)$, which is considered as the infectious particle. ${ }^{29}$ Different forms of PcTS effectively block PrP ${ }^{\text {sc }}$ formation, as revealed by studies on cell-free systems. ${ }^{30}$ Spurred by the efficacy of PcTS compounds to interfere with the $\operatorname{PrP}^{\mathrm{c}}$ to $\mathrm{PrP}^{\mathrm{sc}}$ conversion and accumulation of the toxic form in vitro, phthalocyanines and other cyclic tetrapyrroles such as
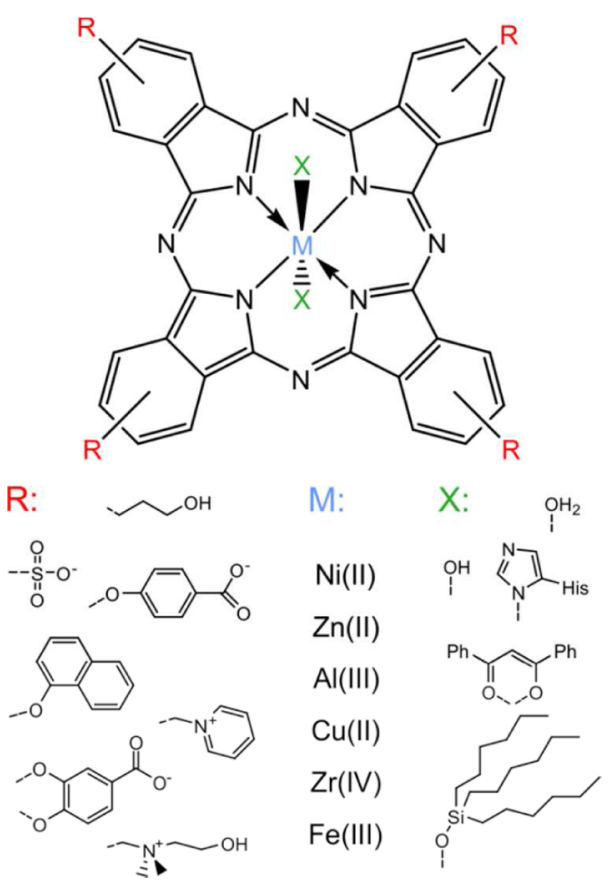

Figure 1. Chemical structure of phthalocyanine compounds. Phthalocyanine core (black) and different modifications at the periphery or the center of the basic scaffold. R, M, and X denote substituents at the periphery of the macrocycle ring, conjugated-metal ions at the phthalocyanine central cavity, and axial ligands for the metal-loaded phthalocyanines species, respectively.

porphyrins were assayed in immortalized cell lines and transgenic mice models (Table 1). ${ }^{8,10,13,31}$ The studies performed on mouse neuroblastoma and rabbit epithelial cell lines chronically infected with scrapie showed that PcTS and its $\mathrm{Ni}$ (II)-coordinated form $(5-10 \mu \mathrm{M})$ were the most effective in decreasing the formation of toxic $\operatorname{PrP}^{\mathrm{sc}}\left(\mathrm{EC}_{50}\right.$ values $\left.\sim 1 \mu \mathrm{M}\right){ }^{10}$ In parallel, studies on transgenic mice overexpressing hamster $\mathrm{PrP}^{\mathrm{c}}$ infected by injection of high doses of brain homogenates from diseased hamsters $263 \mathrm{~K}$ scrapie, revealed that treatment with PcTS $(0.05 \mathrm{~mL}$ of a solution $5 \mathrm{mg} / \mathrm{mL})$ resulted in $50 \%$ of the animals surviving approximately 100 days longer than the untreated controls when drug administration was started on the day of infection. In addition, inactivation of the infectivity derived from brain homogenates of hamster $263 \mathrm{~K}$ scrapie was observed upon incubation with PcTS during the preinfection phase. $^{13,32}$ Further testing with different amounts of infective particles at different times of postinfection revealed that PcTS administration was able to delay disease progression and allow a high-percentage of animals to survive low doses infection, even if PcTS-treatment started one month postinoculation. ${ }^{31}$ By contrast, all non-PcTS-injected animals died when subjected to the same amounts of infective particles. ${ }^{31}$ Thus, PcTS compound was shown to have prophylactic activity when animals are infected with high amounts of infectious particles and it was able to exert also therapeutic effects at lower titers of $\operatorname{PrP}^{\text {sc }}$. Finally, a comparative analysis between PcTS and different metal loaded forms showed that PcTS and Ni(II)loaded PcTS were the most effective phthalocyanines in preventing disease progression, whereas PcTS[Al(III)] had no effect compared with control animals (Table 1). ${ }^{10}$

In addition to the inhibitory activity on $\mathrm{PrP}^{\mathrm{sc}}$ formation, PcTS compounds were also shown to block the aggregation process of other proteins linked to neurodegeneration. For 
Table 1. Anti-Prion Activity of Phthalocyanine Sulfonates in Vitro And in Vivo

\begin{tabular}{|c|c|c|c|}
\hline compd & inhibition of $\operatorname{PrP}^{s c}$ conversion (cultured cells) $\mathrm{EC}_{50}(\mu \mathrm{M})^{d}$ & inhibition of scrapie disease (animal model) ${ }^{e}$ & ref \\
\hline $\mathrm{PcMS}^{a}$ & $0.8 \pm 0.2$ & ++ & 10 \\
\hline $\operatorname{PcDS}^{a}$ & $0.7 \pm 0.1$ & + & 10 \\
\hline $\operatorname{PcTS}^{a}$ & $1.1 \pm 0.6$ & ++ & $10,13,30,31$ \\
\hline $\operatorname{PcTS}[\mathrm{Ni}(\mathrm{II})]$ & $0.7 \pm 0.0$ & ++ & 10,30 \\
\hline $\operatorname{PcTS}[\mathrm{Fe}(\mathrm{III})]$ & $0.7 \pm 0.1$ & + & 10,30 \\
\hline $\operatorname{PcTS}[\mathrm{Mn}(\mathrm{III})]$ & $2.5 \pm 1.2$ & $\mathrm{nd}^{c}$ & 10,30 \\
\hline $\operatorname{PcTS}[\mathrm{Cu}(\mathrm{II})]$ & $3.0 \pm 0.4$ & + & 10,30 \\
\hline $\operatorname{PcTS}[\mathrm{Zn}(\mathrm{II})]$ & $6.1 \pm 4.1$ & $\mathrm{nd}^{c}$ & 10,30 \\
\hline $\operatorname{PcTS}[\mathrm{Al}(\mathrm{III})]$ & $10.0 \pm 1.2$ & - & 10,30 \\
\hline $\mathrm{TMPP}[\mathrm{Fe}(\mathrm{III})]^{b}$ & $0.5 \pm 0.3$ & ++ & 13,30 \\
\hline $\mathrm{TSPhP}[\mathrm{Fe}(\mathrm{III})]^{b}$ & $7.0 \pm 1.0$ & $\mathrm{nd}^{c}$ & 13,30 \\
\hline $\mathrm{DP}(\text { glycol })_{2}[\mathrm{Fe}(\mathrm{III})]^{b}$ & $1.0 \pm 0.1$ & ++ & 13,30 \\
\hline $\mathrm{DP}\left(\mathrm{SO}_{3}{ }^{-}\right)_{2}[\mathrm{Fe}(\mathrm{III})]^{b}$ & $7.5 \pm 0.1$ & $\mathrm{nd}^{c}$ & 13,30 \\
\hline
\end{tabular}

${ }^{a}$ PcMS, PcDS, and PcTS designate compounds with one, two, and four sulfonic acid groups, respectively, per phthalocyanine molecule. ${ }^{b}$ Porphyrins with demonstrated anti-prion activity are included. TMPP $[\mathrm{Fe}(\mathrm{III})]=[$ meso-tetra(4-N-methylpyridyl)porphine iron(III) $] ; \mathrm{TSPhP}[\mathrm{Fe}(\mathrm{IIII})]-\mathrm{TSPhP}$ $=[$ meso-tetra(4-sulfonylphenyl)porphine iron(III) $] ; \mathrm{DP}(\text { glycol })_{2}[\mathrm{Fe}(\mathrm{III})]=[$ deuteroporphyrin IX 2,4-bis(ethylene glycol) iron(III) $]$; $\mathrm{DP}\left(\mathrm{SO}_{3}{ }^{-}\right)_{2}[\mathrm{Fe}(\mathrm{III})]=$ [deuteroporphyrin IX 2,4-bis(sulfonate) iron(III)]. Due to their structural and physicochemical similarities with phthalocyanines, evaluation of porphyrins as anti-amyloid agents became an active area of research. ${ }^{10,13,30,31,43} c_{\text {nd }}=$ not determined. ${ }^{d}$ Reported data correspond to $\mathrm{EC}_{50}(\mu \mathrm{M})$ values, measured as the concentration of inhibitor that gave $50 \%$ of $\operatorname{PrP}^{\mathrm{sc}}$ found in controls, by using a murine neuroblastoma cell line (N2a) chronically infected with scrapie (strain 22L). ${ }^{10,30}{ }^{e}$ Evaluated on a rodent model of scrapie, Tg7 transgenic mice, which overexpress the normally protease-sensitive hamster $\operatorname{PrP}$ and were infected with hamster $263 \mathrm{~K}$ scrapie. The mice were injected (Intraperitoneal injection) with $0.05 \mathrm{~mL}$ of the individual compounds, whose concentrations were in the $5-40 \mathrm{mg} / \mathrm{mL}$ range. The $(++),(+)$, and (-) scores identify compounds that delayed significantly, weakly, or had no effects on the times to disease onset compared with the times for the untreated controls. $^{10,13,31}$
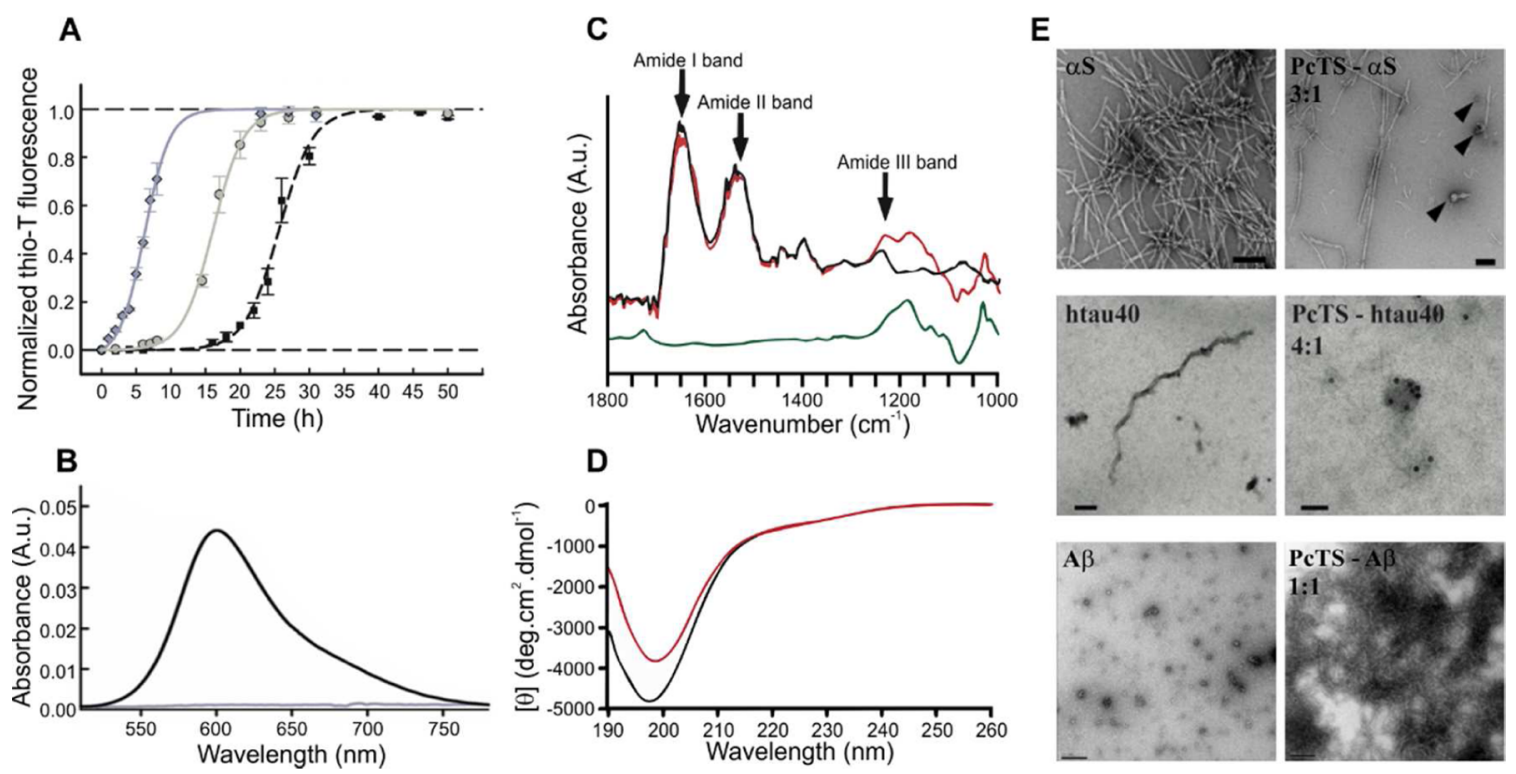

Figure 2. Biophysical characterization of the anti-amyloid activity of PcTS. (A) Kinetics of $\alpha \mathrm{S}(100 \mu \mathrm{M})$ fibrillation measured by the standard Thioflavin T (ThioT) fluorescence assay, in the absence $(\boldsymbol{\square})$ and presence of seeds (sonicated $\alpha \mathrm{S}$ fibrils $(\boldsymbol{\bullet})$ or PcTS-generated $\alpha \mathrm{S}$ aggregates $(\bullet)$ ). The $\alpha \mathrm{S}$ aggregates generated in the presence of PcTS were produced by incubating $\alpha \mathrm{S}$ samples $(100 \mu \mathrm{M})$ with $300 \mu \mathrm{M}$ PcTS. Amyloid aggregation is monitored usually by the standard ThioT fluorescence assay. In the case of phthalocyanine-treated samples, the reliability of ThioT as an indicator of fibril inhibition may be questionable since these small molecules interfere significantly and alter ThioT fluorescence in the absence of proteins due to their intrinsic absorbance and fluorescent properties. However, these effects were not observed at the low concentration (2\%) of PcTS-generated $\alpha \mathrm{S}$ aggregates used in the seeding experiments reported in panel (A). (B) Electronic absorption spectra of soluble (gray line) and unsoluble (black line) fractions of PcTS-generated $\alpha \mathrm{S}$ aggregates. (C, D) Secondary structure analysis of tau oligomers. (C) FTIR spectra of htau40 in the absence (black) and presence of a 15-fold excess of PcTS (red). A control FTIR spectrum of PcTS is also shown (green). (D) Far UV CD spectra of htau40 in the absence (black) and presence of a 15-fold excess of PcTS (red). (E) Transmission electron microscopy of in vitro aggregation of $\alpha \mathrm{S}$, tau and the $\mathrm{A} \beta$ peptide in the absence and presence of PcTS. The concentration of $\alpha \mathrm{S} /$ Tau and $\mathrm{A} \beta$ samples were 100 and $60 \mu \mathrm{M}$, respectively. The protein:PcTS ratios used are indicated in the panels. Images in panels (A), (B), and (E) (top) were adapted with permission from ref 11, Copyright 2009 National Academic of Sciences. Images in panels (C)-(E) (middle) were adapted with permission from ref 17, Copyright 2013 American Chemical Society. TEM images of panel (E) (bottom) were adapted with permission from ref 14, Copyright 2008 WILEY-VCH Verlag GmbH \& Co. 


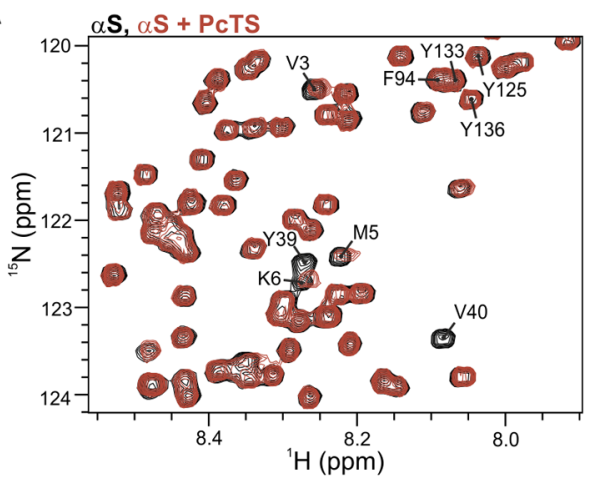

C

$\alpha \mathbf{S}$

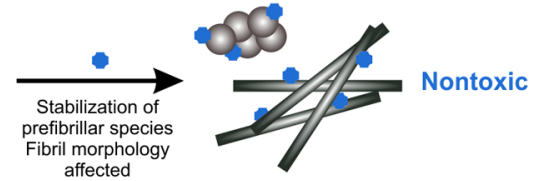

Tau

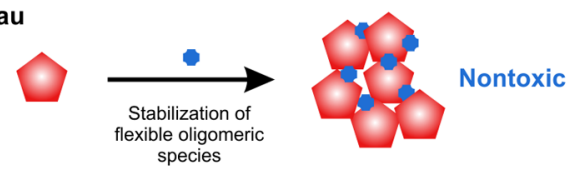

B
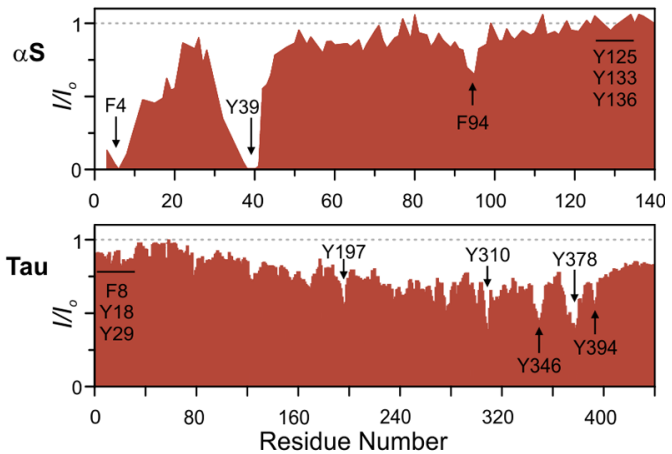

$\mathbf{A} \beta$

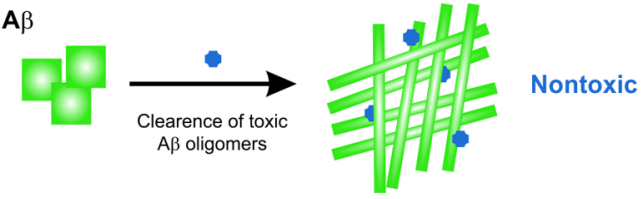

$\operatorname{PrP}$

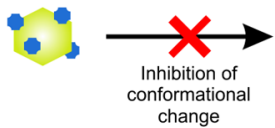

Noninfective

Figure 3. Mechanistic basis behind the anti-amyloid activity of phthalocyanines. (A) Overlaid of $2 \mathrm{D}{ }^{1} \mathrm{H}-{ }^{15} \mathrm{~N} H S Q \mathrm{C}$ spectra of $\alpha \mathrm{S}$ in the absence (black) and presence (red) of PcTS. Crosspeaks broadened significantly or beyond detection are labeled. Figure adapted with permission from ref 11, Copyright 2009 National Academic of Sciences. (B) Interaction profiles of the backbone amide groups of $100 \mu \mathrm{M} \alpha \mathrm{S}$ (top) and tau proteins (bottom) in the presence of 100 and $50 \mu \mathrm{M}$ of PcTS, respectively. The profiles were obtained by comparing the intensities of the NMR signals in the presence $(I)$ and absence $\left(I_{0}\right)$ of PcTS. Black arrows identify the main anchoring sites along the protein sequence. Figures were adapted with permission from ref 11, Copyright 2009 National Academic of Sciences; and ref 17, Copyright 2013 American Chemical Society. (C) Proposed antiaggregation effects exerted by phthalocyanine compounds toward different amyloid proteins. Phthalocyanine compounds (blue spheres) interact with target protein sites and remain bound to different protein species along the aggregation pathway, stabilizing nontoxic aggregation intermediates or noninfective conformations.

instance, PcTS suppressed $\alpha$ S filament assembly, a pathological factor in Parkinson's disease, leading to the formation of a variety of amorphous, nonfibrillar, nontoxic $\alpha \mathrm{S}$ aggregates, in which PcTS molecules were mostly incorporated (Figure 2B, E). ${ }^{11}$ The biophysical and biochemical evidence pointed toward an inhibitory mechanism associated with the trapping of prefibrillar $\alpha \mathrm{S}$ species assembled during early stages of the aggregation pathway, thus preventing their conversion into amyloid-competent species (Figure 2A). ${ }^{11}$ Analysis of the antiamyloidogenic activity of metal-loaded phthalocyanines revealed that the $\mathrm{Zn}$ (II) and $\mathrm{Ni}$ (II) derivatives of phthalocyanine efficiently inhibit the amyloid fibril formation of $\alpha \mathrm{S}$, whereas the PcTS[Al(III)] complexed form was not able to reduce the levels of $\alpha \mathrm{S}$ fibrillar structures. ${ }^{12}$ Interestingly, PcTS was also effective to inhibit the misfolding and aggregation of vesiclebound $\alpha \mathrm{S} .{ }^{19}$ Moreover, the analysis of distinct small molecules showing inhibitory effects on the aggregation of $\alpha \mathrm{S}$ in solution revealed that PcTS was the only compound able to reproduce the anti-amyloid behavior in the lipid environment. ${ }^{19}$

Although less well explored than prion disease, the neuroprotective effect of PcTS was also studied in cellular models of Parkinson's disease. ${ }^{15}$ Evaluation of the toxic effects of $\alpha \mathrm{S}$ toward human neuroblastoma cells demonstrated that the soluble, monomeric state of $\alpha \mathrm{S}$ showed no toxicity, while $\alpha \mathrm{S}$ aggregates decreased cell viability significantly (ca. 60\%). ${ }^{15}$ Interestingly, PcTS $(5-10 \mu \mathrm{M})$ completely rescued the deleterious effects of such aggregates. Similar outcomes were reported recently, showing that PcTS $(10 \mu \mathrm{M})$ reduced the $\alpha \mathrm{S}$ inclusion formation and cytotoxicity in a cell-based model that leads to the formation of intracellular protein inclusions positive for $\alpha \mathrm{S} .^{19}$

The potential of PcTS as an amyloid modulator was also explored on the protein tau and the beta-amyloid $(\mathrm{A} \beta)$ peptide, considered as the pathological components of Alzheimer's disease. PcTS was able to interfere with tau filament assembly in vitro by inducing the conversion of the nontoxic protein state into soluble oligomers characterized by the lack of $\alpha$-helix or $\beta$-sheet structural elements in its molecular architecture (Figure $2 \mathrm{C}-\mathrm{E}) .{ }^{17}$ From a neuroblastoma cell based-assay, it was demonstrated that PcTS $(50 \mu \mathrm{M})$ was also an effective modulator of tau-induced filament formation. ${ }^{17}$ For the case of A $\beta$ peptide, PcTS showed only moderated antiaggregation properties. ${ }^{15}$ Further studies showed that PcTS was also able to induce the clearance of metal-induced toxic $\mathrm{A} \beta$ oligomers and its conversion into an amyloid fibrillar meshwork (Figure 2E), which coincidentally reduced the toxic activity of $\mathrm{A} \beta$ in cellular assays. ${ }^{14}$ Finally, contrasting with the effects observed with metal-free PcTS, a recent study demonstrated that a novel carboxylated PcTS[Zn(II)] derivative $(1-10 \mu \mathrm{M})$ was able to inhibit $\mathrm{A} \beta$ aggregation in vitro, as well as its induced toxicity on neuronal cell lines. ${ }^{18}$ 


\section{STRUCTURAL BASIS OF THE PROTEIN-INHIBITOR MOLECULAR COMPLEXES}

Overall, the picture that emerged from the anti-amyloid properties of PcTS compounds is that the inhibitory mechanism involves direct interactions of the tetrapyrroles with the disease-associated proteins. Thus, a series of elegant works were performed in the last years, in which the structural basis of the interaction between PcTS and amyloid proteins was explored as starting point toward the elucidation of the molecular mechanism behind the anti-amyloid effects exerted by these compounds. The structural characterization of the $\alpha \mathrm{S}$ PcTS complex by NMR spectroscopy revealed that the binding of this compound to the $\mathrm{N}$-terminal region of $\alpha \mathrm{S}$ constitute the first step of the inhibitory process (Figure 3A, B). ${ }^{11}$ The interaction was centered at the aromatic residues Phe- 4 and Tyr-39, which act as independent, noninteractive anchoring groups for the binding of PcTS molecules, an event that occurs with dissociation constants in the low micromolar range $(<10$ $\mu \mathrm{M})$. The study demonstrated that electrostatic interactions between negatively charged sulfonate groups in phthalocyanine and positive moieties on the vicinity of the PcTS binding site, likely provided by lysine residues, might act stabilizing the complex. ${ }^{11}$ The structural elucidation of the $\alpha \mathrm{S}$-PcTS interaction at the residue-specific level provided the framework for the rational design of nonamyloidogenic $\alpha \mathrm{S}$ variants, demonstrating conclusively that specific interactions between the tetrapyrrolic macrocycle and the aromatic Tyr-39 residue represent the key molecular event driving the inhibitory effects of PcTS on $\alpha \mathrm{S}$ fibrillation. ${ }^{11}$

A series of studies focused on metal-conjugated PcTS molecules showed that the interaction profiles of PcTS[Zn(II)] and PcTS[Ni(II)] with $\alpha \mathrm{S}$ is similar to that of metal-free PcTS, characterized by the binding to Phe- 4 and Tyr- 39 at the Nterminus of $\alpha \mathrm{S} .^{12}$ On the other hand, no interaction was detected for the PcTS[Al(III)] variant. ${ }^{12}$ Together with the anti-amyloid performance showed by these compounds on $\alpha \mathrm{S}$, the results confirm the crucial role that specific interactions between the tetrapyrrolic macrocycle and the aromatic Tyr-39 residue play on the anti-amyloid effects that phthalocyanines exert on $\alpha \mathrm{S} .{ }^{11,12}$ Notably, the capabilities of phthalocyanines to bind the residue Tyr-39 of $\alpha \mathrm{S}$ correlated with their activity as amyloid fibrillation inhibitors. Additionally, PcTS also binds directly to the aromatic residues Tyr-39 and Phe-94 of membrane-bound $\alpha S^{19}$ However, that the Tyr-39 residue results critical for the amyloid fibril assembly of $\alpha \mathrm{S}$ in solution but not in its membrane-bound state indicate that both the fibrillation process and the inhibitory mechanism mediated by PcTS on $\alpha \mathrm{S}$ in a membrane environment are different from those occurring in solution. ${ }^{19}$

Consistently with the findings reported for the $\alpha$ S-PcTS complexes, a recent work demonstrated that the ability of PcTS to inhibit formation of tau filaments in vitro and in cells is driven by selective interactions with residues Tyr-197, Tyr-310, Phe-346, Phe-378 and Tyr-394 in the central domain of the protein (Figure $3 \mathrm{~B}$ ) ${ }^{17}$ Regarding to the amyloid $\mathrm{A} \beta$ peptide, although the interaction features of the A $\beta$-PcTS complexes were not characterized with the same level of structural resolution than those described for the interaction of PcTS with the proteins $\alpha \mathrm{S}$ and tau, it was proposed that aromatic residues Tyr-10 and Phe19-20 might be the anchoring groups for PcTS binding. ${ }^{33}$
Finally, a biophysical analysis of the interaction between PcTS and its metal-loaded $\mathrm{Zn}(\mathrm{II})$ and $\mathrm{Al}(\mathrm{III})$ derivatives with $\operatorname{PrP}$ revealed an interaction profile characterized by the presence of at least two phthalocyanine binding sites with micromolar affinities in the order: PcTS $\left(K_{\mathrm{d}}=18.0 \mu \mathrm{M} \pm 0.4\right)$ $\approx \operatorname{PcTS}[\mathrm{Zn}(\mathrm{II})]\left(K_{\mathrm{d}}=24 \mu \mathrm{M} \pm 1\right) \gg \operatorname{PcTS}[\mathrm{Al}(\mathrm{III})]\left(K_{\mathrm{d}}=\right.$ $180 \mu \mathrm{M} \pm 13) .{ }^{34}$ Although no high-resolution structural data is available, it was suggested that the binding would be driven primarily by specific interactions between the macrocycle ring of PcTS and aromatic side-chains of $\operatorname{PrP} .^{34}$ Notably, the strength of binding determined for the protein complexes of PcTS and its conjugated $\mathrm{Zn}(\mathrm{II})$ and $\mathrm{Al}(\mathrm{III})$ derivatives correlated directly with the anti-amyloid and toxic protective effects exerted by these compounds in cells and animal models infected with $\operatorname{PrP}^{\text {sc }} .10,30$

\section{STRUCTURE-ACTIVITY RELATIONSHIP AND INHIBITORY MECHANISM}

The identification and development of more effective antiamyloid compounds requires a better understanding of their structure-activity relationships. Recently, structure-based discovery led to structural optimization and design of efficient small molecule inhibitors targeting amyloid filament assembly. ${ }^{35,36}$ Although the structural requirements for the efficient anti-amyloid activity of phthalocyanines remain unclear, their ability to block different types of disease-associated protein aggregation raises the possibility that these cyclic tetrapyrrolic compounds have a common mechanism of action to impair the formation of a variety of pathological aggregates.

As mentioned in the previous section, the inhibitory mechanism exerted by phthalocyanines on amyloid assembly is proposed to be a direct consequence of their interaction with target proteins. These molecular interactions are influenced strongly by (i) the high-aromatic character of the cyclic tetrapyrrole ring system, that contributes importantly to the ability of these molecules to bind strongly and selectively to a protein via $\pi-\pi$ interactions with aromatic residues; (ii) the presence of negatively or positively charged substituents located at the periphery of the macrocycle, that can mediate electrostatic interaction with positive or negative patches on the amyloid proteins, and (iii) the different properties of the metal ion coordinated to the center of the tetrapyrrolic ring system, such as its residual charge or its coordination geometry preferences. Additionally, another metal-sensitive property of phthalocyanines that may be critical to its anti-amyloid activity is their tendency to self-associate via $\pi-\pi$ stacking interactions. ${ }^{10}$

Previous studies investigating the effect of the degree of sulfonation of phthalocyanines on its anti-prion activity revealed that increasing the number of sulfonated substituents at peripheral positions influences markedly their solubility and distribution in biological fluids, but had little effect on the inhibition of $\mathrm{PrP}^{\mathrm{sc}}$ formation both in vitro and in vivo. ${ }^{10}$ This finding led to the hypothesis that $\pi-\pi$ stacking interactions directed by the polyaromatic ring system of PcTS are more relevant for its anti-prion activity than electrostatic interactions mediated by sulfonate groups. In the same direction, the structural characterization of the interaction between PcTS and the protein $\alpha \mathrm{S}$ revealed that the basis for the inhibitory effect of this compound relies on its binding to the $\mathrm{N}$-terminus sequence of $\alpha \mathrm{S},{ }^{11}$ a molecular event that would be primarily driven by $\pi-\pi$ stacking interactions between the aromatic side-chain of Tyr-39 and the aromatic ring system of phthalocyanines; the 
contribution of electrostatic interactions to the binding affinity of PcTS molecules for $\alpha \mathrm{S}$ is almost negligible. ${ }^{11}$ Additionally, even if the involvement of $\pi-\pi$ interactions between sidechains of aromatic amino acids and the ring system of cyclic tetrapyrroles in the formation of protein-ligand complexes has been reported by NMR spectroscopy, X-ray diffraction, and modeling studies, ${ }^{37,38}$ further investigation of these proteinligand interactions, for example, through molecular simulation and/or docking-based analysis, will be essential to establish more firmly the mechanism of the PcTS binding to amyloid proteins.

The most precise information related to the structural and physicochemical properties of PcTS compounds that are key to their anti-amyloid activity arose from studies on metal-loaded phthalocyanines. These studies revealed that metal incorporation into the architecture of PcTS influences the inhibitory effects of phthalocyanines in different ways. For example, conjugation with $\mathrm{Ni}(\mathrm{II})$ or $\mathrm{Zn}$ (II) result in PcTS variants with in vitro and in vivo anti-prion activity and inhibition of $\alpha \mathrm{S}$ amyloid fibril formation in vitro. ${ }^{10,12,30}$ On the other hand, the PcTS[Al(III)] conjugate was the least effective. Thus, the activity of phthalocyanines against disease-associated protein aggregation seems to be relatively insensitive to the degree of sulfonation at peripheral locations but is highly dependent on the nature of the metal ions coordinated at the center of the molecule. ${ }^{10,30}$ More recently, it was demonstrated that dissimilarities in anti-amyloid potency are dictated by the distinct self-association tendencies of phthalocyanine: PcTS $\operatorname{PcTS}[\mathrm{Ni}(\mathrm{II})]>\operatorname{PcTS}[\mathrm{Zn}(\mathrm{II})] \gg \operatorname{PcTS}[\mathrm{Al}(\mathrm{III})] \approx 0 .{ }^{10,12}$ The planarity and aromaticity of phthalocyanines is determinant for such self-association reactions, which can be impaired or enhanced by the type of the conjugated metal ion. Thus, the degree of phthalocyanine self-association via aromaticaromatic stacking interactions correlates with their binding capabilities to target proteins and, more importantly, determines their efficiency as anti-amyloid agents. ${ }^{10,12}$

This behavior results particularly interesting in the context of the current development of anti-amyloid molecules, since it is considered that self-association could be a common signature of aggregation inhibitors identified in high-throughput screenings. ${ }^{39}$ At this juncture, a comparative analysis between phthalocyanines and other amyloid inhibitors with selfassociation capability can be revealing. For example, contrasting with the well-defined binding profile of phthalocyanines to $\alpha \mathrm{S}$, polyphenol's inhibitors like lacmoid or congo red are characterized by a more widespread interaction, covering the first 100 amino acids of the protein sequence. ${ }^{40}$ Interestingly, this interaction pattern is reminiscent of the protein interaction with lipid vesicles and membranes. ${ }^{40}$ These differences in the protein-ligand recognition pattern seem to be correlated to the anti-amyloid behavior of these compounds. While the molecular interactions of congo red and lacmoid with $\alpha \mathrm{S}$ are consistent with a mechanism based on the sequestration of protein monomers into colloidal complexes and inhibition of $\alpha \mathrm{S}$ self-assembly, ${ }^{41,42}$ this hypothesis is not sustained for phthalocyanines. ${ }^{12,17}$ Indeed, the specific binding observed for PcTS to Phe- 4 and Tyr-39 at the N-terminus of $\alpha \mathrm{S},{ }^{11}$ or even the selective aromatic interactions of PcTS at the central region of tau protein, ${ }^{17}$ contrast markedly with a nonselective, protein sequestration mechanism mediated by self-association of the anti-amyloid compounds. Moreover, for a range of small molecules, the anti-amyloid effects were ascribed to the interaction with intermediate amyloid structures, hypothesizing that the inhibitory binding would be conformational-dependent rather than sequence-dependent. ${ }^{9,35}$ Instead, structural characterization reported for phthalocyanines demonstrate conclusively that these molecules interact with the monomeric, nontoxic form of the proteins, indicating that the amyloid blocking effects mediated by specific PcTS-induced perturbation of aromatic residues at well-defined regions of the target proteins might be related to a loss of function of aromatic side chains involved in the filament-assembly mechanism. On this potential scenario, the molecular recognition between inhibitor molecules and amyloidogenic sequences in the target protein could compromise early intra- and intermolecular interactions necessary for amyloid structural transitions, impairing the formation of the amyloidogenic core and efficiently interfering with the formation of toxic species and amyloid fibrils (Figure 3C).

In summary, the limited number of amyloid inhibitors that have progressed through clinical trials could be explained by three main factors: (i) the complexity of the structural conversions occurring during the amyloid aggregation process, (ii) the absence of high-resolution structural information about the binding modes and nature of the molecular interactions involved in protein-inhibitor complexation, and (iii) the scarcity of research intended to understand the physicochemical requirements of inhibitory molecules determining their antiamyloid activity. In this work, we have discussed several of these aspects related to phthalocyanines and, at the same time, provided a firm basis to understand and predict the relevant factors directing phthalocyanine-protein molecular recognition and driving phthalocyanine self-association. In this regard, the planarity and aromaticity of the ring system appear as critical factors because it is a common feature of all amyloid blocking phthalocyanines, whereas the type and nature of the central metal ions and peripheral substituents can vary widely. Indeed, the versatility of phthalocyanines to condone the conjugation of different metal ions and a wide range of peripheral substituents, which in turn can modulate physicochemical properties such as their solubility and distribution in biological fluids, emphasize the potential of this scaffold for further optimizations in terms of pharmacokinetics, side effects, toxicity, and delivery to the brain. Overall, we believe that the findings discussed in this Account constitute an important contribution to the design of small molecule amyloid inhibitors with enhanced therapeutic efficiency.

\section{AUTHOR INFORMATION}

\section{Corresponding Author}

*E-mail: fernandez@iidefar-conicet.gob.ar/cfernan@gwdg.de.

Notes

The authors declare no competing financial interest.

\section{Biographies}

Ariel A. Valiente-Gabioud received his $\mathrm{PhD}$ in Biological Sciences in 2015 working under the supervision of Prof. Dr. Claudio O. Fernández at the MPLbioR and IIDEFAR, Rosario, Argentina. His research focused on the structural biology of amyloid aggregation. Currently, he is a Postdoctoral student at the Max Planck Institute of Neurobiology, Munich, Germany.

Marco C. Miotto is a PhD student at the MPLbioR and IIDEFAR, Rosario, Argentina. His research is focused on the study of the metallobiology of neurodegenerative diseases. 
Maria E. Chesta is a Postdoctoral student at the MPLbioR and IIDEFAR, Rosario, Argentina. Her research is focused on the screening and discovery of novel inhibitors of disease-associated protein aggregation.

Verónica A. Lombardo is Assistant Investigator at the MPLbioR and IIDEFAR, Rosario, Argentina. She uses zebrafish disease models for understanding the molecular basis of cardiac and neurological disorders.

Andres Binolfi is Associate Investigator at the MPLbioR and IIDEFAR, Rosario, Argentina. He is interested in the intracellular structural properties of amyloid-related proteins.

Claudio O. Fernández is Principal Investigator and Full Professor. He is the Director of the (1) Max Planck Laboratory for Structural Biology, Chemistry and Molecular Biophysics of Rosario (MPLbioR, UNR-MPIbpC), associated with the MPIbpC of Göttingen, Germany, and the (2) Instituto de Investigaciones para el Descubrimiento de Fármacos de Rosario (IIDEFAR, UNR-CONICET). His field of research involves NMR-based structural biology, molecular biophysics, and cellular biology applied to the study of protein misfolding diseases.

\section{ACKNOWLEDGMENTS}

C.O.F. thanks Universidad Nacional de Rosario, CONICET, the Ministry of Education of Argentina, the Ministry of Health of Argentina, ANPCyT, FONCyT, Fundacion Medife, Fundacion Bunge y Born, the Max Planck Society and the Alexander von Humboldt Foundation for financial support.

\section{ABBREVIATIONS}

$\mathrm{PD}, \mathrm{AD}$, and CJD, Parkinson's, Alzheimer's and CreutfeldJakob's diseases, respectively; $\operatorname{PrP}$, prion protein; $\operatorname{PrP}^{\mathrm{c}}$ and $\mathrm{PrP}^{\mathrm{sc}}$, native cellular and misfolded scrapie prion protein, respectively; $\alpha \mathrm{S}$, alpha-synuclein; $\mathrm{A} \beta$, amyloid beta peptide; PcTS, phtalocyanine tetrasulfonate; $\mathrm{EC}_{50}$, effective concentration giving 50\% inhibition; dpi, days postinfection; HSQC, heteronuclear single quantum coherence; NMR, nuclear magnetic resonance

\section{REFERENCES}

(1) Soto, C. Unfolding the role of protein misfolding in neurodegenerative diseases. Nat. Rev. Neurosci. 2003, 4, 49-60.

(2) Chiti, F.; Dobson, C. M. Protein misfolding, functional amyloid, and human disease. Annu. Rev. Biochem. 2006, 75, 333-366.

(3) Haass, C.; Selkoe, D. J. Soluble protein oligomers in neurodegeneration: lessons from the Alzheimer's amyloid betapeptide. Nat. Rev. Mol. Cell Biol. 2007, 8, 101-112.

(4) Liu, T.; Bitan, G. Modulating self-assembly of amyloidogenic proteins as a therapeutic approach for neurodegenerative diseases: strategies and mechanisms. ChemMedChem 2012, 7, 359-374.

(5) Bulic, B.; Pickhardt, M.; Schmidt, B.; Mandelkow, E. M.; Waldmann, H.; Mandelkow, E. Development of tau aggregation inhibitors for Alzheimer's disease. Angew. Chem., Int. Ed. 2009, 48, $1740-1752$.

(6) Schenk, D.; Basi, G. S.; Pangalos, M. N. Treatment strategies targeting amyloid beta-protein. Cold Spring Harbor Perspect. Med. 2012, 2, a006387.

(7) Masuda, M.; Suzuki, N.; Taniguchi, S.; Oikawa, T.; Nonaka, T.; Iwatsubo, T.; Hisanaga, S.; Goedert, M.; Hasegawa, M. Small molecule inhibitors of alpha-synuclein filament assembly. Biochemistry 2006, 45, 6085-6094.

(8) Caughey, B.; Caughey, W. S.; Kocisko, D. A.; Lee, K. S.; Silveira, J. R.; Morrey, J. D. Prions and transmissible spongiform encephalopathy (TSE) chemotherapeutics: A common mechanism for anti-TSE compounds? Acc. Chem. Res. 2006, 39, 646-653.
(9) Ehrnhoefer, D. E.; Bieschke, J.; Boeddrich, A.; Herbst, M.; Masino, L.; Lurz, R.; Engemann, S.; Pastore, A.; Wanker, E. E. EGCG redirects amyloidogenic polypeptides into unstructured, off-pathway oligomers. Nat. Struct. Mol. Biol. 2008, 15, 558-566.

(10) Caughey, W. S.; Priola, S. A.; Kocisko, D. A.; Raymond, L. D.; Ward, A.; Caughey, B. Cyclic tetrapyrrole sulfonation, metals, and oligomerization in antiprion activity. Antimicrob. Agents Chemother. 2007, 51, 3887-3894.

(11) Lamberto, G. R.; Binolfi, A.; Orcellet, M. L.; Bertoncini, C. W.; Zweckstetter, M.; Griesinger, C.; Fernandez, C. O. Structural and mechanistic basis behind the inhibitory interaction of PcTS on alphasynuclein amyloid fibril formation. Proc. Natl. Acad. Sci. U. S. A. 2009, 106, 21057-21062.

(12) Lamberto, G. R.; Torres-Monserrat, V.; Bertoncini, C. W.; Salvatella, X.; Zweckstetter, M.; Griesinger, C.; Fernandez, C. O. Toward the discovery of effective polycyclic inhibitors of alphasynuclein amyloid assembly. J. Biol. Chem. 2011, 286, 32036-32044.

(13) Priola, S. A.; Raines, A.; Caughey, W. S. Porphyrin and phthalocyanine antiscrapie compounds. Science 2000, 287, 1503-1506.

(14) Park, J. W.; Ahn, J. S.; Lee, J. H.; Bhak, G.; Jung, S.; Paik, S. R. Amyloid fibrillar meshwork formation of iron-induced oligomeric species of Abeta 40 with phthalocyanine tetrasulfonate and its toxic consequences. ChemBioChem 2008, 9, 2602-2605.

(15) Lee, E. N.; Cho, H. J.; Lee, C. H.; Lee, D.; Chung, K. C.; Paik, S. R. Phthalocyanine tetrasulfonates affect the amyloid formation and cytotoxicity of alpha-synuclein. Biochemistry 2004, 43, 3704-3715.

(16) Taniguchi, S.; Suzuki, N.; Masuda, M.; Hisanaga, S.; Iwatsubo, T.; Goedert, M.; Hasegawa, M. Inhibition of heparin-induced tau filament formation by phenothiazines, polyphenols, and porphyrins. J. Biol. Chem. 2005, 280, 7614-7623.

(17) Akoury, E.; Gajda, M.; Pickhardt, M.; Biernat, J.; Soraya, P.; Griesinger, C.; Mandelkow, E.; Zweckstetter, M. Inhibition of tau filament formation by conformational modulation. J. Am. Chem. Soc. 2013, 135, 2853-2862.

(18) Tabassum, S.; Sheikh, A. M.; Yano, S.; Ikeue, T.; Handa, M.; Nagai, A. A carboxylated Zn-phthalocyanine inhibits fibril formation of Alzheimer's amyloid beta peptide. FEBS J. 2015, 282, 463-476.

(19) Fonseca-Ornelas, L.; Eisbach, S. E.; Paulat, M.; Giller, K.; Fernandez, C. O.; Outeiro, T. F.; Becker, S.; Zweckstetter, M. Small molecule-mediated stabilization of vesicle-associated helical alphasynuclein inhibits pathogenic misfolding and aggregation. Nat. Commun. 2014, 5, 5857.

(20) Ben-Hur, E.; Chan, W.-S. Phthalocyanines in Photobiology and Their Medical Applications. In The Porphyrin Handbook; Guilard, K. M. K. M. S., Ed.; Academic Press: Amsterdam, 2003; pp 1-35.

(21) Sekkat, N.; van den Bergh, H.; Nyokong, T.; Lange, N. Like a bolt from the blue: phthalocyanines in biomedical optics. Molecules 2012, 17, 98-144.

(22) Kinsella, T. J.; Baron, E. D.; Colussi, V. C.; Cooper, K. D.; Hoppel, C. L.; Ingalls, S. T.; Kenney, M. E.; Li, X.; Oleinick, N. L.; Stevens, S. R; Remick, S. C. Preliminary clinical and pharmacologic investigation of photodynamic therapy with the silicon phthalocyanine photosensitizer pc 4 for primary or metastatic cutaneous cancers. Front. Oncol. 2011, 1, 14.

(23) McKeown, N. B. The Synthesis of Symmetrical Phthalocyanines. In The Porphyrin Handbook; Guilard, K. M. K. M. S., Ed.; Academic Press: Amsterdam, 2003; pp 61-124.

(24) Kobayashi, N. Design, Synthesis, Structure, and Spectroscopic and Electrochemical Properties of Phthalocyanines. Bull. Chem. Soc. Jpn. 2002, 75, 1-19.

(25) Sorokin, A. B. Phthalocyanine metal complexes in catalysis. Chem. Rev. 2013, 113, 8152-8191.

(26) Kasuga, K.; Tsutsuo, M. Some new developments in the chemistry of metallophthalocyanines. Coord. Chem. Rev. 1980, 32, 6795.

(27) Palewska, K.; Sworakowski, J.; Lipiński, J. Molecular aggregation in soluble phthalocyanines - Chemical interactions vs. $\pi$-stacking. Opt. Mater. 2012, 34, 1717-1724. 
(28) Snow, A. W. Phthalocyanine Aggregation. In The Porphyrin Handbook; Guilard, K. M. K. M. S., Ed.; Academic Press: Amsterdam, 2003; pp 129-176.

(29) Caughey, B.; Baron, G. S. Prions and their partners in crime. Nature 2006, 443, 803-810.

(30) Caughey, W. S.; Raymond, L. D.; Horiuchi, M.; Caughey, B. Inhibition of protease-resistant prion protein formation by porphyrins and phthalocyanines. Proc. Natl. Acad. Sci. U. S. A. 1998, 95, 1211712122.

(31) Priola, S. A.; Raines, A.; Caughey, W. Prophylactic and therapeutic effects of phthalocyanine tetrasulfonate in scrapie-infected mice. J. Infect. Dis. 2003, 188, 699-705.

(32) Abdel-Haq, H.; Lu, M.; Cardone, F.; Liu, Q. G.; Puopolo, M.; Pocchiari, M. Efficacy of phthalocyanine tetrasulfonate against mouseadapted human prion strains. Arch. Virol. 2009, 154, 1005-1007.

(33) Yao, S.; Cherny, R. A.; Bush, A. I.; Masters, C. L.; Barnham, K. J. Characterizing bathocuproine self-association and subsequent binding to Alzheimer's disease amyloid beta-peptide by NMR. J. Pept. Sci. 2004, 10, 210-217.

(34) Dee, D. R.; Gupta, A. N.; Anikovskiy, M.; Sosova, I.; Grandi, E.; Rivera, L.; Vincent, A.; Brigley, A. M.; Petersen, N. O.; Woodside, M. T. Phthalocyanine tetrasulfonates bind to multiple sites on nativelyfolded prion protein. Biochim. Biophys. Acta, Proteins Proteomics 2012, 1824, 826-832.

(35) Jiang, L.; Liu, C.; Leibly, D.; Landau, M.; Zhao, M.; Hughes, M. P.; Eisenberg, D. S. Structure-based discovery of fiber-binding compounds that reduce the cytotoxicity of amyloid beta. eLife 2013, 2, e00857.

(36) Herrmann, U. S.; Schutz, A. K.; Shirani, H.; Huang, D.; Saban, D.; Nuvolone, M.; Li, B.; Ballmer, B.; Aslund, A. K.; Mason, J. J.; Rushing, E.; Budka, H.; Nystrom, S.; Hammarstrom, P.; Bockmann, A.; Caflisch, A.; Meier, B. H.; Nilsson, K. P.; Hornemann, S.; Aguzzi, A. Structure-based drug design identifies polythiophenes as antiprion compounds. Sci. Transl. Med. 2015, 7, 299ra123.

(37) Liu, D.; Williamson, D. A.; Kennedy, M. L.; Williams, T. D.; Morton, M. M.; Benson, D. R. Aromatic Side Chain-Porphyrin Interactions in Designed Hemoproteins. J. Am. Chem. Soc. 1999, 121, $11798-11812$.

(38) Weinert, E. E.; Phillips-Piro, C. M.; Marletta, M. A. Porphyrin pi-stacking in a heme protein scaffold tunes gas ligand affinity. J. Inorg. Biochem. 2013, 127, 7-12.

(39) McGovern, S. L.; Caselli, E.; Grigorieff, N.; Shoichet, B. K. A common mechanism underlying promiscuous inhibitors from virtual and high-throughput screening. J. Med. Chem. 2002, 45, 1712-1722.

(40) Rao, J. N.; Dua, V.; Ulmer, T. S. Characterization of alphasynuclein interactions with selected aggregation-inhibiting small molecules. Biochemistry 2008, 47, 4651-4656.

(41) Feng, B. Y.; Toyama, B. H.; Wille, H.; Colby, D. W.; Collins, S. R.; May, B. C.; Prusiner, S. B.; Weissman, J.; Shoichet, B. K. Smallmolecule aggregates inhibit amyloid polymerization. Nat. Chem. Biol. 2008, 4, 197-199.

(42) Lendel, C.; Bertoncini, C. W.; Cremades, N.; Waudby, C. A.; Vendruscolo, M.; Dobson, C. M.; Schenk, D.; Christodoulou, J.; Toth, G. On the mechanism of nonspecific inhibitors of protein aggregation: dissecting the interactions of alpha-synuclein with Congo red and lacmoid. Biochemistry 2009, 48, 8322-8334.

(43) Lee, B. I.; Lee, S.; Suh, Y. S.; Lee, J. S.; Kim, A. K.; Kwon, O. Y.; Yu, K.; Park, C. B. Photoexcited Porphyrins as a Strong Suppressor of beta-Amyloid Aggregation and Synaptic Toxicity. Angew. Chem., Int. Ed. 2015, 54, 11472-11476. 